\title{
Organizational Agility: The Key to Improve Organizational Performance
}

\author{
Wageeh A. Nafei ${ }^{1}$ \\ ${ }^{1}$ University of Sadat City, Menoufia, Egypt \\ Correspondence: Wageeh A. Nafei, University of Sadat City, Menoufia, Egypt. E-mail: \\ dr.wageeh1965@yahoo.com
}

Received: August 9, 2015

Accepted: January 19, 2016

Online Published: February 25, 2016

doi: 10.5539/ibr.v9n3p97

URL: http://dx.doi.org/10.5539/ibr.v9n3p97

\begin{abstract}
Purpose: The purpose of this study is to highlight the significant role of Organizational Agility (OA) in improving Organizational Performance (OP) at the pharmaceutical industry in Egypt.

Research Design/Methodology: To assess positive OA, refer to (OA Questionnaire, Jaworski, \& Kohli 1993), and OP (OP Questionnaire \& Darroch, 2003; Pathirage et al., 2007; and Chen \& Mohamed, 2008). The data was collected from 310 employees. Out of the 356 questionnaires that were distributed, 310 usable questionnaires were returned, a response rate of $87 \%$. Multiple Regression Analysis (MRA) was used to confirm the research hypotheses.

Findings: The research has found that there is significant relationship between OA and OP. The finding reveals that OA affects OP. Accordingly, the study provided a set of recommendations including the necessity to pay more attention to OA as a key source for improving OP.

Practical implications: This research contributes to boosting scientific research, particularly in terms of testing the model content, as well as studying the study variables and the factors affecting them. In addition, this research pointed to the need for organizations to practice OA in order to improve OP.

Originality/value: This research dealt with $\mathrm{OA}$ in terms of its concept and dimensions, in addition to dealing with the role of OA in improving OP at the pharmaceutical industry in Egypt.
\end{abstract}

Keywords: organizational agility, organizational performance

\section{Introduction}

In the beginning of $21^{\text {st }}$ century, the world faced considerable changes in all aspects, especially great changes in the communicational channels. These changes require organizations to revise their strategic priorities and visions (Sharifi \& Zhang, 1999, 2001). The organizational agility (OA) is one of the methods for responding to these changes and revolution factors. Indeed, the $\mathrm{OA}$ is a new paradigm for engineering competitive organizations and firms.

Since human mind capabilities are limited in terms of grasping important changes that take place in the environment surrounding it, so has the current business environment for any organization in the world become complicated and highly dynamic (Zain et al., 2005). Therefore, it has become necessary that organizations in dire need for light movement of human capital be characterized with sensing agility, decision-making, and agility in carrying out work properly. This should be done in a manner which makes them engaged at work, devoting all their efforts, feelings and realization in order to achieve the objectives of the organization (Markos \& Sridevi, 2010; Warr \& Inceoglu, 2012).

Continuous change is increasingly the new normal rather than the exception in contemporary organizations (Brown \& Eisenhardt, 1998). As a result, interest in OA has grown exponentially for practitioners and researchers (Tallon \& Pinsonneault, 2011).

In the unpredictable and competitive world of today, the organizations must have different competitive features to compete; otherwise, they will move towards annihilation. One of these features that organizations need in turbulent environments is agility. Agility provides the organization with the possibility of quick response and compatibility with environment and allows the organization to improve its efficiency (Yeganegi \& Azar, 2012). 
OA has become the topic of interest of both academics and practitioners in recent years. Nine out of ten executives ranked OA as both critical to business success and growing in importance over time in a McKinsey \& Company survey (Sull, 2009).

OA plays an important role in the life of the organization as it provides personnel with knowledge, high skills, restructuring and organizational processes, employing new technology (Sherehiy, 2008).

Research on OA is emerging in information systems fields (Izza et al., 2008) due to the extensive reliance of contemporary organizations on information, in general, and information system in particular. OA refers to organizations' ability to thrive by sensing and responding to environmental changes which has become critically important nowadays when the business environment is getting highly competitive and turbulent. It is being regarded as a key business factor and a potential enabler to organization's competitiveness (Mathiassen \& PriesHeje, 2006),

This study is structured as follows: Section one is introductory. Section two presents the literature review. Section three presents the research model. Section four presents the research questions and hypotheses. Section five explains the research strategy. Empirical results are provided in section six. Section seven handles the main findings. Finally, section eight presents the research recommendations.

\section{Literature Review}

\subsection{Organizational Agility Concept}

The concept of agility needs to be well grounded in management theory (Yusuf et al., 1999). Early in the 1990s, the new solution for managing a dynamic and changing environment emerged-agility. Agile manufacturing is the ability of surviving and prospering in a competitive environment of continuous and unpredictable change by reacting quickly and effectively to changing markets, driven by customer-defined products and services (Gunasekaran, 1999).

The creators of "agility" concept at the Iacocca Institute, of Lehigh University (USA) defined it as a manufacturing system with capabilities (hard and soft technologies, human resources, educated management, information) to meet the rapidly changing needs of the marketplace (speed, flexibility, customers, competitors, suppliers, infrastructure, responsiveness). Agility is the successful application of competitive bases such as speed, flexibility, innovation, and quality by the means of the integration of reconfigurable resources and best practices of knowledge-rich environment to provide customer-driven products and services in a fast changing environment (Yusuf et al., 1999). Agility emphasizes the speed and flexibility as the primary attributes of an agile organization (Gunasekaran, 1999).

An equally important attribute of agility is the effective response to change and uncertainty (Goldman et al., 1995). Some authors state that responding to change in proper ways and exploiting and taking advantages of changes are the main factors of agility (Sharifi \& Zhang, 1999).

Agility refers to the proactive responses to changes (Bessant et al., 2001). Agility refers to the use of changes as inherent opportunities in turbulent environment (Sharifi \& Zhang, 2001).

Agility refers to the ability to survive and progress in the variable and unpredictable environment (Dove, 2001).

Organizational flexibility represents an organization's capacity to adjust its internal structures and processes in a predetermined response to changes in the environment. Adaptability underlies the fit of organizational operations to their environment while flexibility emphasizes the readiness of organizational resources and the ease of resource mobilization. The "agility" concept encompasses both flexibility and adaptability. Agility, as a business concept, was coined in a manufacturing context-particularly in relation to flexible manufacturing systems (Christopher \& Towill, 2001).

Agility is a new concept in contemporary administrative thought. One writer has defined the process of agility in terms of the capabilities necessary to achieve light movement in the organization (Sherehiy, 2008). Agility is the ability to respond to unpredictable changes with quick response and profitability (Erande \& Verma, 2008).

Agility is an organizational ability to react quickly and effectively to an environment which can change radically (Janssen, 2010).

The concept of agility means rapid, agile, and active movement. Also, agility refers to the ability of rapid and easy movement and rapidly thinking with a thoughtful method. The root or origin of agility is derived from agile production and this is a concept that has been presented during later years. The agile production has been accepted as a successful strategy by producers that prepare them for a considerable performance (Mehrabi et al., 2013). 
According to the different definitions of the word agility, the concept of speed and quick response, and also the concepts of group work and common goal regarding the word organization, can be inferred. Agility can be defined as swiftness and quick response of a harmonious group to the changes made by the environment surrounding them in order to reach a goal (Yeganegi \& Azar, 2012).

OA is the organization's ability to respond quickly and effectively to unexpected opportunities, in addition to providing, in advance, solutions that meet potential needs (Nelson \& Harvey, 1995).

$\mathrm{OA}$ is the ability to survive and grow in an unexpected competitive environment of constant change through rapid response to changing markets and through meeting the desires and needs of customers, whether of products or services (Gunasekaran, 1999). OA is the successful application of the competition rules, such as speed, flexibility, innovation and quality, through the means of integration of resources and the restructuring of best practices in the environment of technical knowledge, through the provision of services or products that meet customers' preferences in light of a rapidly changing environment (Yusuf et al., 1999).

OA is the organization's ability to work comfortably in a quickly and consistently changing and fragmented global market environment, through producing high quality and effective performance (Tsourveloudis \& Valavanis, 2002).

OA enables the organization to carry out a series of specific tasks successfully, in addition to managing the opportunities and risks in the business activities effectively (Ardichvile et al., 2003).

OA makes organizations more responsive to market trends, and faster in terms of the delivery of products and services compared to non-agile ones. OA is composed of three dimensions of the sensor agility, decision-making, and agility practice and application (Sambamurthy et al., 2003).

$\mathrm{OA}$ is not only "flexible" to cater for predictable changes but also able to respond and adapt to unpredictable changes quickly and efficiently (Oosterhout et al., 2006).

OA can be viewed as the state of organizational performance in terms of flexibility and adaptability and is attainable through organization's activities. In particular, from the process-based perspective, OA is a set of processes that allow an organization to sense changes and respond efficiently and effectively in timely and cost-effective manner in the internal and external environments. Sensing refers to an organization's ability to detect, capture and interpret organizational opportunities (Seo \& Paz, 2008).

Responding represents an organizational ability to mobilize and transform resources to react to the opportunities that it senses (Gattiker et al., 2005; Oosterhout et al., 2006).

These two capabilities must be aligned to optimally obtain OA. OA is the organizational capacity to sensor response successfully to the opportunities and threats in the market in a timely manner (Overby et al., 2006).

$\mathrm{OA}$ is a proactive management strategy that aims at maintaining the organization's resources and achieving the desires of customers in a timely manner (Hitt et al., 2007). The concept of OA is derived from performance characteristics of an agile organization and is rooted in two related concepts-"organizational adaptability" and "organizational flexibility". Organizational adaptability focuses on how an organization's form, structure, and degree of formalization influence its ability to quickly adapt to its business environment (Sherehiy et al., 2007).

OA consists of several key elements. They are (1) speed and flexibility, (2) responding to changes in the surrounding environment, (3) high quality products, (4) products and services of accurate information, (5) interacting with social issues and the environment, (6) different technologies collecting, and (7) internal integration inside the institutions and among each other (Sherehiy, 2008).

$\mathrm{OA}$ is the process of arrangement, and abolition of business units, markets and industries to re-focus on differentiated core capabilities (Hill \& Jones, 2009).

OA is a package of ideas that aims at continuous improvement, flat organizational structures, work teams, stopping waste or loss, efficient use of resources, and managing the chain of preparation. Japanese companies have adopted the concept of OA in terms of reducing costs through the removal of waste (David, 2009).

$\mathrm{OA}$ is a construction of three basic elements. They are (1) sensing agility, (2) decision-making, and (3) acting using agility and its application (Pavlou \& El Sawy, 2010).

OA quickly meets customer requests, offers new products, and gets on strategic alliances or gets rid of them. This means that organizations are in an urgent need of strategic alliances in order to solve the problems of its customers, rather than providing products or one service. The fundamental reason behind the necessity of OA is searching for the core capabilities, on the one hand, and identifying the business environment and capturing 
opportunities, on the other hand (McCarthy et al., 2010).

$\mathrm{OA}$ is the manufacturing system for physical and non-physical technology, human resources, educated management and information in order to meet the rapidly changing needs of the market in a manner that achieves the desires and needs of the customers in time (Park, 2011).

In light of this, the researcher does identify OA as the organization's ability to achieve its objectives, through the development of its products increasing knowledge of its human resources, effecting the development of the organization and lightening its movement in a rapidly changing environment.

\subsection{Organizational Agility Dimensions}

The dimensions of the OA are three main types. They are sensing agility, decision-making agility and acting agility (Park, 2011).

\subsubsection{Sensing Agility}

Sensing agility is the organizational capacity to inspect and monitor events and changes in the surrounding environment (customer preferences changes, the movements of the new competitors, new technology) in a timely manner (Park, 2011). The task of sensing means the strategic monitoring of environmental events that could have an impact on organizational strategy, competitive work, and future performance, including several activities such as access to information related to the events which show environmental change, on the one hand, and getting rid of the trivial information, on the other hand, in light of predetermined foundations and rules (El-Sawy, 1985). This task is related to decision-making and its execution (Daft \& Weick, 1984; Dutton \& Duncan, 1987). It is interested in organizational adaptation to change in the surrounding environment (Smircich \& Stubbart, 1985).

\subsubsection{Decision-Making Agility}

Decision-making agility process is the ability to collect, accumulate, restructure and evaluate relevant information according to a variety of sources to explain the implications of the business without delay, and to identify opportunities and threats based on the interpretation of events, along with the development of action plans, which direct the reconfiguration of resources and the development of new competitive procedures (Park, 2011). Decision-making task consists of several interrelated activities, which explain many events and identify opportunities and threats in the surrounding environment. The task of decision-making focuses on collecting information from multiple and diverse sources in order to understand the implications of their work (Thomas et al., 1993). The task of decision-making seeks to capture the utmost opportunities and minimize the impact of threats on the life of the organization (Houghton et al., 2004).

\subsubsection{Acting Agility/Practicing}

The acting task consists of a set of activities for re-assembling organizational resources and modifying business processes on the basis of the principles of work resulting from the task of decision-making in order to address the change that occurs in the surrounding environment (Eisenhardt \& Martin, 2000). Organizations can change the business processes by various procedures and resources, redesigning the organizational structure of the organization (Dutton \& Duncan, 1987; Thomas et al., 1993). The three-dimensions of OA can be explained through the following table (Park, 2011).

Table 1 . The dimension of organizational agility

\begin{tabular}{cc}
\hline Dimensions of OA & Clarification of dimensions \\
\hline Sensing Agility & Detecting and attracting important business at one time \\
Decision-Making & Interpreting events, identifying opportunities and threats and taking the actual plans in time \\
Agility & Reshaping organizational resources drastically and modifying business processes and the provision of services or \\
Acting Agility & new products to market in time \\
\hline
\end{tabular}

Source: Park, (2011). The Dynamics of Opportunity and threat Management in Turbulent Environments: The Role Information Technologies, PhD Dissertatio.

\subsection{Organizational Performance}

In English, the term "performance" is derived from "to perform" which means "doing work, achieving a mission or realizing a given activity. It is a reflection of the organization's ability and aptitude to realize its goals (Eccles, 
1991).

OP is the ability of the organization to achieve its long-term goals (Robins \& Wiersema, 1995). It is that which exceeds the normal average performance, besides being a part of a series of excellent performance (Privett, 1983).

OP is a determinant of its very existence. Systematic or abrupt decline in OP level may lead to organizational death or mortality (Baum \& Singh, 1994), a situation that occurs when an organization fails, closes down its operations, and disbands its constituent elements (Carroll \& Delacroix, 1982).

Despite the large corpus of research and studies on OP, no agreement on the concept of OP is found. In spite of this difference, most researchers express their OP through the success achieved by the organization in achieving its objectives. OP is a reflection of the organization's ability to achieve its goals, or in other words, the organization's ability to achieve long-term goals (Miller \& Broamiley, 1990).

OP can be defined as a combination of resources, capabilities of the organization that are being used efficiently and effectively in order to achieve its objectives (Collis \& Montgomrey, 1995). OP is the level of the outputs of the organization after conducting operations on its inputs. OP is the output of the activities that occur within the organization (Wit \& Meyer, 1998).

Hence, after a thorough review of the different concepts of OP, it can be argued that OP in its simplest form is the desired results which the organization seeks to achieve efficiently and effectively.

Darroch (2003) maintains that the dimensions of OP are in two basic dimensions of OP. They can be explained as follows:

\subsubsection{Comparative Performance}

Refers to the understanding of the different categories of employees to the level of profitability of the organization where they work, the market share, and the level and speed of growth of the organization compared to organizations working in the same area.

\subsubsection{Internal Performance}

Refers to the understanding of the different categories of employees to the level of the OP to which they belong in the short term and long-term, and also the possibility of achieving the OP targets set for the organization, both in the short term and long term.

\section{Research Model}

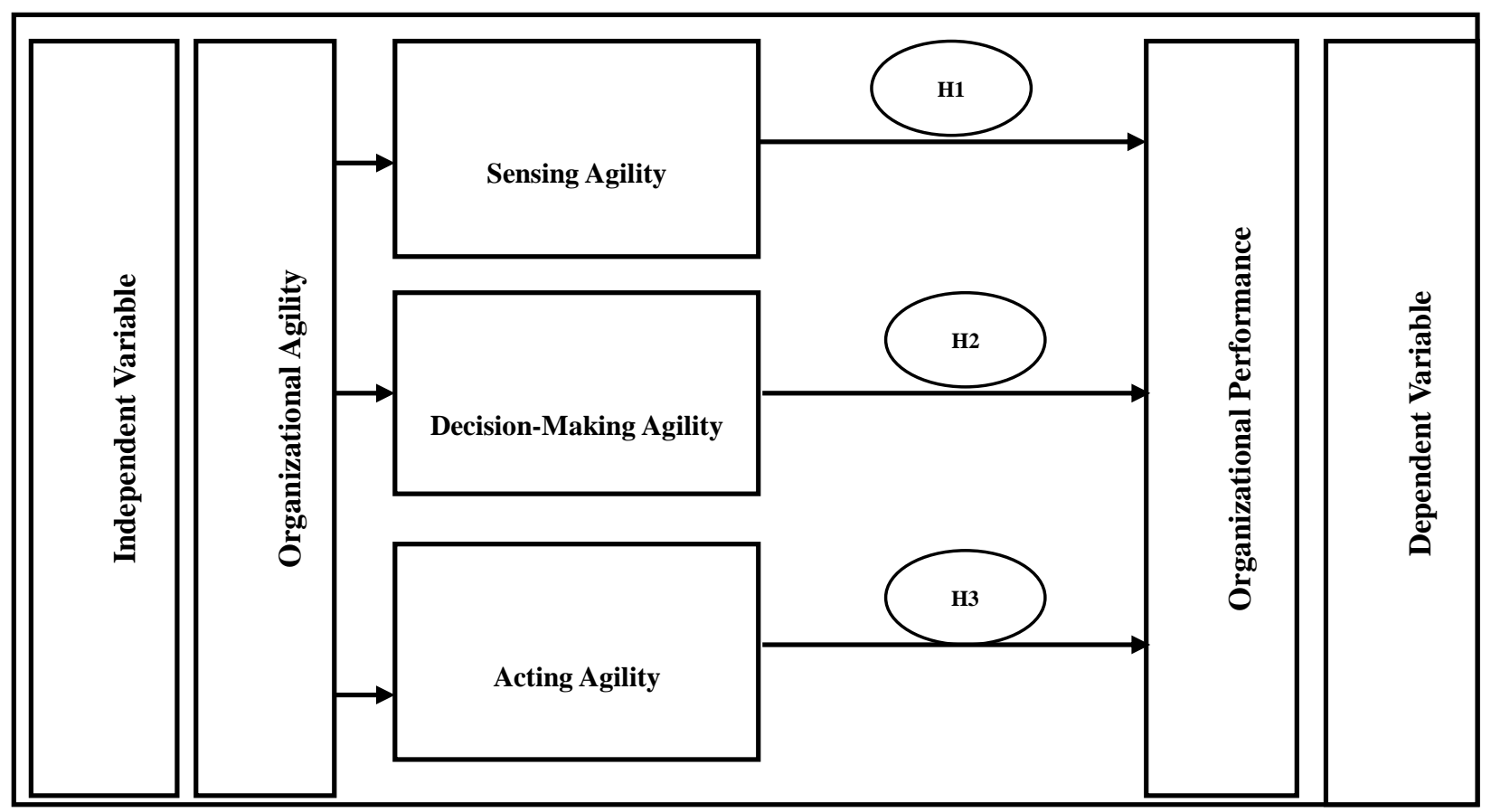

Figure 1. Proposed comprehensive conceptual model 
The proposed comprehensive conceptual model is presented in Figure 1. The diagram below shows that there is one independent variable of OA. There is one dependent variable of OP. It shows the rational link between the two types of observed independent and dependent variables.

The research framework suggests that OA plays a significant role in improving OP. OA as measured consisted of sensing agility, decision-making agility and acting agility (Jaworski \& Kohli, 1993). OP is measured in terms of comparative performance and internal performance (Darroch, 2003; Pathirage et al., 2007; and Chen \& Mohamed, 2008).

\section{Research Questions and Hypotheses}

The researcher found the research problem through two sources. The first source is to be found in previous studies, and it turns out that there is a lack in the number of literature reviews that dealt with the analysis of the relationship between OA and OP at the pharmaceutical industry in Egypt. This called for the researcher to test this relationship in the Egyptian environment. The second source is the pilot study, which was conducted in an interview with (30) employees in order to identify the relationship between OA and OP. The researcher found, through the pilot study, several indicators, notably the important and vital role that could be played by OA in reinforcing $\mathrm{OP}$ at the pharmaceutical industry in Egypt. As a result of the discussions given above, the research questions of this study are as follows:

Q1: What is the nature and extent of the relationship between OA (sensing agility) and OP at the pharmaceutical industry in Egypt?

Q2: What is the nature of the relationship between OA (decision-making agility) and OP at the pharmaceutical industry in Egypt?

Q3: What is the extent of the relationship between OA (acting agility) and OP at the pharmaceutical industry in Egypt?

The following hypotheses were developed to test if there is significant correlation between OA and OP.

H1: OA (sensing agility) of employees has no statistically significant effect on OP at the pharmaceutical industry in Egypt.

$\mathrm{H} 2$ : There is no statistically significant relationship between OA (decision-making agility) and $\mathrm{OP}$ at the pharmaceutical industry in Egypt.

H3: There is no statistically significant impact of OA (acting agility) of employees and OP at the pharmaceutical industry in Egypt.

\section{Research Strategy}

\subsection{Population and Sample}

The population of the study included all employees at the pharmaceutical industry in Egypt. This sector includes five companies. They are Delta for the Pharmaceutical Industry, Egyptian International Pharmaceutical Industries (Eipico), Pharma Sweden, Egypt Otsu, and Egyptian Chemicals and drugs. This explains why the population of this study includes 4,783 employees. The random sampling was used for collecting the primary data as it was difficult to get all of the items of the research population because of time limitations. The stratified random sample was used while selecting items from the different categories of employees. The following equation determines the sampling size (Daniel, 1999):

$$
\mathrm{n}=\frac{N \times(Z)^{2} \times P(1-P)}{d^{2}(N-1)+(Z)^{2} \times P(1-P)}
$$

Accordingly, the sample size has become 356 employees at the pharmaceutical industry in Egypt.

Table 2. Distribution of the sample size

\begin{tabular}{|c|c|c|c|}
\hline Egyptian Pharmaceutical Companies & Employees & Percentage & Sample Size \\
\hline 1. Delta for the Pharmaceutical Industry & 1500 & $31.4 \%$ & $356 \times 31.4 \%=112$ \\
\hline 2. Egyptian International Pharmaceutical Industries (Eipico) & 1833 & $38.3 \%$ & $356 \times 38.3 \%=136$ \\
\hline 3. Pharma Sweden & 850 & $17.8 \%$ & $35617.8 \%=63$ \\
\hline 4. Egypt Otsu & 350 & $7.3 \%$ & $356 \times 7.3 \%=26$ \\
\hline 5. Egyptian Chemicals and drugs & 250 & $5.2 \%$ & $356 \times 5.2 \%=19$ \\
\hline Total & 4783 & $100 \%$ & $356 \times 100 \%=356$ \\
\hline
\end{tabular}

Source: Personnel Department at Pharmaceutical Industry in Egypt, 2015. 
Proportionality with the number of employees in the research population is proved in Table 2. By using the lists of employees at the Staff Affairs Department, pharmaceutical industry in Egypt random choice of categories was attained. Table 3 illustrates the features of sample units.

Table 3. Characteristics of items of the sample

\begin{tabular}{|c|c|c|c|}
\hline \multicolumn{2}{|c|}{ Variables } & Number & Percentage \\
\hline \multirow{4}{*}{ 1-Job Title } & Physicians & 129 & $41.6 \%$ \\
\hline & Nurses & 149 & $48.1 \%$ \\
\hline & Administrative Staff & 32 & $10.3 \%$ \\
\hline & Total & 310 & $100 \%$ \\
\hline \multirow{3}{*}{ 2-Sex } & Male & 120 & $38.7 \%$ \\
\hline & Female & 190 & $61.3 \%$ \\
\hline & Total & 310 & $100 \%$ \\
\hline \multirow{3}{*}{ 3-Marital Status } & Single & 100 & $32.3 \%$ \\
\hline & Married & 210 & $67.7 \%$ \\
\hline & Total & 310 & $100 \%$ \\
\hline \multirow{4}{*}{ 4-Age } & Under 30 & 125 & $40.3 \%$ \\
\hline & From 30 to 45 & 120 & $38.7 \%$ \\
\hline & Above 45 & 65 & $21.0 \%$ \\
\hline & Total & 310 & $100 \%$ \\
\hline \multirow{4}{*}{ 5-Educational Level } & Secondary school & 100 & $32.3 \%$ \\
\hline & University & 150 & $48.4 \%$ \\
\hline & Post Graduate & 60 & $19.4 \%$ \\
\hline & Total & 310 & $100 \%$ \\
\hline \multirow{4}{*}{ 6-Period of Experience } & Less than 5 years & 100 & $32.3 \%$ \\
\hline & From 5 to 10 & 80 & $25.8 \%$ \\
\hline & More than 10 & 130 & $41.9 \%$ \\
\hline & Total & 310 & $100 \%$ \\
\hline
\end{tabular}

\subsection{Procedure}

The goal of this study was to identify the significant role of OA in improving OP. A survey research method was used to collect data in this study.

The questionnaire included three questions, relating to OA, OP and biographical information of employees at the pharmaceutical industry in Egypt.

Data collection took approximately two months. About 356 survey questionnaires were distributed by employing diverse modes of communication such as in person and post.

Multiple follow-ups yielded 310 statistically usable questionnaires. Survey responses were $87 \%$.

\subsection{Research Variables and Methods of Measuring}

The 15-item scale OA section is based on Jaworski and Kohli (1993). There were three items measuring sensing agility, five items measuring decision-making agility, and seven items measuring acting agility.

The 7-item scale of OP section is based on Darroch (2003); Pathirage et al. (2007); and Chen and Mohamed, (2008). There were three items measuring comparative performance, and four items measuring internal performance.

Responses to all items scales were anchored on a five (5) point Likert scale for each statement ranging from (5) "full agreement" (4) for "agree" (3) for "neutral" (2) for "disagree" and (1) for "full disagreement".

\subsection{Methods of Data Analysis and Testing Hypotheses}

The researcher has employed the following methods: (1) The Alpha Correlation Coefficient (ACC), (2) Multiple Regression Analysis (MRA), and (3) the statistical testing of hypotheses which includes F-test and T-test. They are found in SPSS.

\section{Hypotheses Testing}

Before testing the hypotheses and research questions, descriptive statistics were performed to find out means and 
standard deviations of OA and OP.

Table 4. Showing the mean and standard deviations of OA and OP

\begin{tabular}{crcc}
\hline Variables & The Dimension & Mean & Standard Deviation \\
\hline \multirow{3}{*}{ OA } & Sensing Agility & 3.8556 & 1.16595 \\
& Decision-Making Agility & 3.6348 & 1.35678 \\
& Acting Agility & 4.0645 & 0.77384 \\
& Total Measurement & $\mathbf{3 . 8 8 1 5}$ & $\mathbf{0 . 9 5 3 9 5}$ \\
\hline \multirow{2}{*}{ OP } & Comparative Performance & 3.7398 & 0.97894 \\
& Internal Performance & 4.2137 & 0.84528 \\
& Total Measurement & $\mathbf{4 . 0 1 0 6}$ & $\mathbf{0 . 6 7 0 3 2}$ \\
\hline
\end{tabular}

According to Table 4, the first issue examined was the different facets of OA (sensing agility, decision-making agility and acting agility).

According to Table 4, among the various facets of OA, most of the respondents identified the presence of sensing agility $(M=3.85 S D=1.165)$, decision-making agility $(M=3.63, S D=1.356)$, and acting agility $(M=4.064$, $S D=0.773)$.

The second issue examined was the different facets of OP (comparative performance and internal performance).

According to Table 4, among the various facets of OP, most of the respondents identified the presence of comparative performance $(M=3.73, S D=0.978)$, and internal performance $(M=4.213, S D=0.845)$.

\subsection{Evaluating Reliability}

Data analysis was conducted. All scales were first subjected to reliability analysis. ACC was used to assess the reliability of the scales. Item analysis indicated that dropping any items from the scales would not significantly raise the alphas.

Table 5. Reliability of OA and OP

\begin{tabular}{crcc}
\hline Variables & The Dimension & Number of Statement & ACC \\
\hline \multirow{4}{*}{ OA } & Sensing Agility & 3 & 0.8785 \\
& Decision-Making Agility & 5 & 0.9601 \\
& Acting Agility & 7 & 0.8153 \\
& Total Measurement & $\mathbf{1 5}$ & $\mathbf{0 . 9 4 2 8}$ \\
\hline \multirow{3}{*}{ OP } & Comparative Performance & 3 & 0.6650 \\
& Internal Performance & 4 & 0.7627 \\
& Total Measurement & $\mathbf{7}$ & $\mathbf{0 . 6 5 3 0}$ \\
\hline
\end{tabular}

To assess the reliability of the data, Cronbach's alpha test was conducted. Table 5 shows the reliability results for OA and OP. All items had alphas above 0.60 and were, therefore, excellent, according to Langdridge's (2004) criteria.

Table 5 presents the reliability of OA. The reliabilities of sensing agility, decision-making agility and acting agility are generally higher. The 15 items of OA are reliable because the ACC is 0.9428 . The sensing agility, which consists of 3 items, is reliable because the ACC is 0.8785 . Decision-making agility, which consists of 5 items is, reliable because the ACC is 0.9601 . Acting agility, which consists of 7 items, is reliable because the ACC is 0.8153 . Thus, the internal consistency of OA can be acceptable.

Table 5 presents the reliability of OP. The 7 items of OP are reliable because the ACC is 0.6530 . The comparative performance, which consists of 3 items, is reliable because the ACC is 0.6650 . Furthermore, internal performance, that consists of 4 items, is reliable because the ACC is 0.7627 . Thus, the reliability of OP can be acceptable.

Accordingly, three scales were defined, OA (15 variables), where ACC represented about 0.9428 , and OP (7 variables), where ACC represented 0.6530 . 


\subsection{The Correlation among the Research Variables}

Table 6. Means, standard deviations and intercorrelations among variables

\begin{tabular}{ccccc}
\hline Variables & Mean & Std. Deviation & OA & OP \\
\hline Organizational Agility & 3.8815 & 0.95395 & 1.000 & \\
Organizational Performance & 4.0106 & 0.67032 & $0.847^{* *}$ & 1.000 \\
\hline
\end{tabular}

Table 6 shows correlation coefficients between the research variables, and results indicate the presence of significant correlation between variables (OA, and OP). The level of OA of employees is high $(\mathrm{Mean}=3.88$; $\mathrm{SD}=0.953)$, which led to higher $\mathrm{OP}(\mathrm{Mean}=4.0106 ; \mathrm{SD}=0.67032)$.

The Table shows the correlation between OA and OP $(\mathrm{R}=0.847 ; \mathrm{P}<0.01)$ implying that the high level of $\mathrm{OA}$ increases OP.

\subsection{Organizational Agility and Organizational Performance}

The relationship between OA and OP is determined. The hypothesis to be tested is:

There is no relationship between OA (Sensing Agility, Decision-Making Agility, and Acting Agility) and OP at the pharmaceutical industry in Egypt.

Table 7. Correlation between OA and OP

\begin{tabular}{|c|c|c|c|c|}
\hline & bles & $\begin{array}{c}\text { Dependent } \\
\text { Variable } \\
\end{array}$ & $\begin{array}{c}\text { Pearson } \\
\text { Correlation } \\
\end{array}$ & Sign \\
\hline \multirow{4}{*}{$O A$} & Sensing Agility & \multirow{3}{*}{$\mathrm{OP}$} & $0.827^{* *}$ & 0.000 \\
\hline & Decision-Making Agility & & $0.789^{* *}$ & 0.000 \\
\hline & Acting Agility & & $0.715^{* *}$ & 0.000 \\
\hline & \multicolumn{2}{|c|}{ Total Measurement } & $0.847^{* *}$ & 0.000 \\
\hline
\end{tabular}

Note. $* *$ Correlation is significant at 0.01 level.

Based on Table 7, correlation between OA (sensing agility) and OP is 0.827 . For OA (decision-making agility) and OP, the value is 0.789 whereas OA (acting agility) and OP shows correlation value of 0.715 . The overall correlation between OA and OP is 0.847 .

6.4 The Relationship between $O A$ (Sensing Agility) and $O P$

Table 8. MRA results for OA (Sensing Agility) and OP

\begin{tabular}{llcc}
\hline \multicolumn{1}{c}{ The Variables of $\mathbf{O A}$ (sensing agility) } & Beta & $\mathbf{R}$ & $\mathbf{R}^{2}$ \\
\hline 1. $\quad$ The organization has been slow in terms of detecting changes that & $0.372^{* *}$ & $0.790^{* *}$ & 0.624 \\
occur in customer preferences for products. & & 0.417 \\
2. $\quad$ The organization has been slow in terms of detecting changes that & $0.289^{* *}$ & $0.646^{* *}$ & 0.609 \\
occur in the movements of competitors. & $0.260^{*}$ & $0.781^{* *}$ & 0.827 \\
3. $\quad$ The organization has been slow to detect changes in technology. & & 0.684 \\
- MCC & & 221.150 \\
- DC & & 3,306 \\
- $\quad$ Degree of Freedom & & 3.78 \\
- Indexed F & & 0.000 \\
\hline
\end{tabular}

Table 8 proves that there is a relationship between OA (sensing agility) and OP. As a result of the value of $R^{2}$, the 3 independent variables of sensing agility can explain $68.4 \%$ of the total differentiation in OP level.

For the results of a structural analysis of the MRA, the direct effect of OA (sensing agility) and OP is obtained. 
Because MCC is 0.827 , there is enough empirical evidence to reject the null hypothesis.

\subsection{The Relationship between OA (Decision-Making Agility) and $O P$}

As Table 9 proves, the MRA resulted in the R of 0.796 . This means that OP has been significantly explained by the 5 independent variables of $\mathrm{OA}$ (decision-making agility).

Furthermore, the $\mathrm{R}^{2}$ of 0.634 indicates that the percentage of the variable interprets the whole model, that is, $63.4 \%$.

It is evident that the five independent variables justified $63.4 \%$ of the total factors of OP. Hence, $36.6 \%$ are explained by the other factors. Therefore, there is enough empirical evidence to reject the null hypothesis.

Table 9. MRA results for OA (decision-making agility) and OP

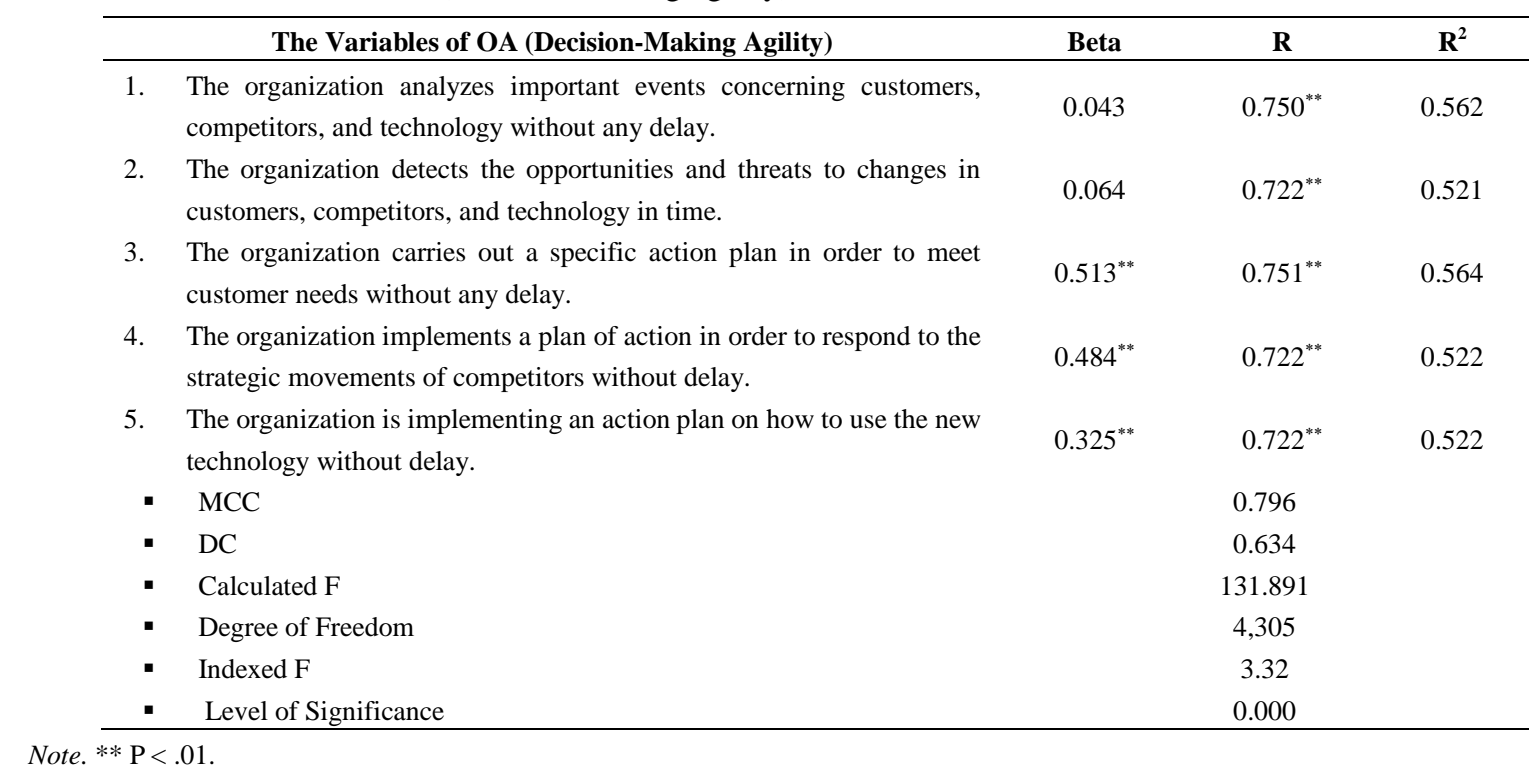

6.6 The Relationship between $O A$ (Acting Agility) and $O P$

Table 10. MRA results for OA (Acting Agility) and OP

\begin{tabular}{llccc}
\hline \multicolumn{1}{c}{ The Variables of OA (Acting Agility) } & Beta & $\mathbf{R}$ & $\mathbf{R}^{2}$ \\
\hline 1. & The organization can reconfigure its resources in the proper time. & $0.232^{*}$ & $0.378^{* *}$ & 0.143 \\
2. & The organization can re-adjust operations carried out in a timely manner. & $0.235^{* *}$ & $0.233^{* *}$ & 0.056 \\
3. The organization can use new technology in the proper time. & 0.028 & $0.396^{* *}$ & 0.157 \\
4. The organization can introduce new products in the proper time. & $0.220^{* *}$ & $0.148^{* *}$ & 0.022 \\
5. The organization can change prices quickly in the proper time. & 0.174 & $0.675^{* *}$ & 0.455 \\
6. The organization can change strategic things in the proper time. & $0.454^{* *}$ & $0.627^{* *}$ & 0.527 \\
7. The organization can solve customers' needs and complaints without delay. & $0.564^{* *}$ & $0.701^{* *}$ & 0.492 \\
- & & 0.814 & \\
- $\quad$ DC & & 0.663 & \\
- & & 84.691 & \\
- & Dalculated F & & 7,302 \\
- & & 2.63 \\
- & Legree of Freedom & & 0.000 \\
\hline
\end{tabular}

Note. $* * \mathrm{P}<0.01 * \mathrm{P}<0.05$.

Table 10 proves that there is a relationship between OA (acting agility) and OP. As a result of the value of $\mathrm{R}^{2}$, the 7 independent variables of acting agility can explain $66.3 \%$ of the total differentiation in OP level.

For the results of a structural analysis of the MRA, the direct effect of OA (acting agility) and OP is obtained. 
Because MCC is 0.814 , there is enough empirical evidence to reject the null hypothesis.

\section{Research Findings}

The present study on analyzing the relationship between OA and OP has revealed the following results:

1) Sensing agility, which is an integral part of OA, significantly and positively influences OP.

2) $\mathrm{OA}$ (decision-making agility) positively related with $\mathrm{OP}$.

3) Acting agility, which is an integral part of OA, positively correlated with OP.

4) OA plays an important role in influencing OP. The study pointed out that the availability of OA (sensing agility, decision-making agility, and acting agility) plays an important role in influencing the dimensions of OP.

\section{Recommendations}

The managers at the pharmaceutical industry in Egypt might be able to improve OP through the following:

1) Broader usage of the various means of sensing agility, especially detecting and attracting important business at one time. This will highly improve OP, as the field study has proved.

2) Reconstructing decision-making agility, besides paying attention to interpreting events, identifying opportunities and threats and taking the actual plans in time. The field study has proved the adverse effect of existing structures on OP.

3) Adopting more acting agility, besides reshaping organizational resources drastically and modifying business processes and the provision of services or new products to market in time. This will entail their feeling of empowerment as the field study has concluded the existence of a strong positive impact of decentralization and authority delegation on OP.

4) The managers should be more attentive towards organizational factors; especially sensing agility, decision-making agility, and acting agility. This could lead to conformity of the factors, and more success and effectiveness of the industrial sector in the community.

5) It is necessary to pay attention to the impact of the types of OA on OP for employees and for the purpose of obtaining an effective impact of OA on OP. Also, it is necessary to prioritize the order of the dimensions of OA in order to achieve the goals of the pharmaceutical industry in Egypt.

6) Enhancing factors that lead to OP in accordance with contemporary management trends in a changing environment.

7) Focusing on the strength of the relationship between OA and OP in light of the organizations involved to achieve the objectives of the pharmaceutical industry in Egypt.

8) Developing and promoting trust between individuals working in the organization, since the availability of this element is a strategic and incomparable dimension. The dimension of experience is no more sufficient alone to achieve organizational success but rather to create strategic movement agility and encourage workers towards working engagement

9) It is important for senior administrations of the organizations under study to form specialized teams and conduct seminars and lectures in order to achieve speed, flexibility, responsiveness and adaptability to work with the basic components of the agile organization.

10) It is necessary to provide data and information base in the organizations under study in a way which helps clarify vision to decision makers as regards personnel engagement in work in order to make strategic decisions, results of which may constitute a change in the future of the organizations of the current study.

\section{Research Implications}

Managers at the pharmaceutical industry in Egypt might be able to improve OP through OA. OP may be affected by OA. It helps employees pay attention to professional standards.

OA may exist with the help of top management at the pharmaceutical industry in Egypt. This is achieved by taking employees interests into account. In this way, absenteeism and turnover will be lower. Productivity and profitability will be higher.

\section{Limitations and Future Research}

There are some limitations of this study. Firstly, the data was collected from employees at the pharmaceutical industry in Egypt. Therefore, the generalization of the results must be made with caution, especially in case of applying to a different country. Secondly, findings may not be generalized to other industrial companies in 
Egypt. Thirdly, a small sample is used in this study.

There are several areas for future research. The present study helped in OA as accepted by the researchers concerned. Still, more research is needed in the following topics (1) the impact of OA on the development of the creative aptitudes of employees, (2) the relationship between OA and job engagement, (3) the impact of OA on the work involvement in the governmental sector, (4) similar studies should be undertaken in other sectors in Egypt such as education, and tourism, and (5) future studies should examine the relationship between OA and quality of work life.

\section{Conclusion}

This study attempted to investigate the relationship between OA and OP. The study proved that there is a statistical significant relationship between OA and OP. It revealed that OA and OP proved to be related.

Policy-makers may make use of the present study. It will highlight the impact of OA on OP.

The study findings present valuable understanding for managers regarding how to make organizations engaged to enhancing their employees, learning effectiveness, improving professional practices, and reducing turnover.

OA has positive impact on OP at the pharmaceutical industry in Egypt. Top management of the organizations can enhance OP by developing the dimensions of OA.

The pharmaceutical industry in Egypt can increase OP by ensuring OA within its organizations.

Research on OA and OP increased over the past decade. However, this rapid growth caused several problems, including the need to better understand the conceptual similarities and differences between various forms of OA and OP, as well as their antecedents and consequences. Overall, this is an important and dynamic field of research, and we are hopeful that this paper will help speed progress in this area by highlighting several key issues that need more attention.

\section{References}

Ardichvili, A., Cardozob, R., \& Rayc, S. (2003). A Theory of Entrepreneurial Opportunity Identification and Development. Journal of Business Venturing, 18, 105. http://dx.doi.org/10.1016/S0883-9026(01)00068-4

Baum, J., \& Singh, J. (1994). Organizational Niches and the Dynamics of Organizational Mortality. American Journal of Sociology, 100, 346-80. http://dx.doi.org/10.1086/230540

Bessant, J., Knowles, D., Francis, D., \& Meredith, S. (2001). Developing the Agile Enterprise, Agile Manufacturing: The $21^{s t}$ Century Competitive Strategy. Elsevier Science.

Brown, S., \& Eisenhard, K. (1998). Competing on the Edge. Boston, MA: Harvard Business School Press.

Carroll, G., \& Delacroix, J. (1982). Organizational Mortality in the Newspaper Industries of Argentina and Ireland: An Ecological Approach. Administrative Science Quarterly, 27, 169-198. http://dx.doi.org/10.2307/2392299

Chen, L., \& Mohamed, S. (2008). Contribution of knowledge management activities to organisational business performance. Journal of Engineering, Design and Technology, 6(3), 269-285. http://dx.doi.org/10.1108/17260530810918289

Christopher, M., \& Towill, D. (2001). An Integrated Model for the Design of Agile Supply Chains. International Journal of Physical Distribution \& Logistics Management, 31(4), 235-246. http://dx.doi.org/10.1108/09600030110394914

Collis, D., \& Montgomrey, C. (1995). Competing on Resources: Strategy in the 1995.

Daft, L., \& Weick, E. (1984). Toward a Model of Organizations as Interpretive Systems. Academy of Management Review, 9, 284-295.

Darroch, J. (2003). Developing A Measure of Knowledge Management Behaviors and Practices. Journal of Knowledge Management, 7(5), 41-54. http://dx.doi.org/10.1108/13673270310505377

David, F. (2009). Strategic Management-Concepts and Cases (12th ed.). Prentice-Hill Pearson Education International Inc. U.S.A.

Dove, R. (2001). Responsibility: The language, structure, and culture of the agile enterprise. New York: Wiley.

Dutton, J., \& Duncan, R. (1987). The Creation of Momentum for Change through the Process of Strategic Issue Diagnosis. Strategic Management Journal, 8, 279-295. http://dx.doi.org/10.1002/smj.4250080306

Eccles, V. (1991). The Value Evolution: Addressing Larger Implications of Intellectual Capital and Intangibles 
Perspective. Journal of Intellectual Capital, 1(1), 1.

Eisenhardt, M., \& Martin, J. (2000). Dynamic Capabilities: What Are They? Strategic Management Journal, 21, 1105-1121. http://dx.doi.org/10.1002/1097-0266(200010/11)21:10/11<1105::AID-SMJ133>3.0.CO;2-E

El Sawy, O. (1985). Personal Information Systems for Strategic Scanning in Turbulent Environments: Can the CEO Go Go-Line? MIS Quarterly, 9(1), 53-60. http://dx.doi.org/10.2307/249273

Erande, A., \& Verma, A. (2008). Measuring Agility of Organizations-A Comprehensive Agility Measurement Tool (CAMT). Old Dominion University, Proceedings of The 2008 IAJC-IJME International Conference.

Gattiker, T., Chen, D., \& Goodhue, D. (2005). Agility through Standardization: A Crm/Erp Application. In F. R. Jacobs, \& B. Elliot (Eds.), Strategic Erp Extension and Use (pp. 87-96). Stanford Business Books.

Goldman, S., Nagel, R., \& Preiss, K. (1995). Agile Competitors and Virtual Organizations: Strategies for Enriching the Customer. New York: Van. Nostrand Reinhold.

Gunasekaran, A. (1999). Agile Manufacturing: A Framework for Research and Development. International Journal of Production Economics, 62, 87-105. http://dx.doi.org/10.1016/S0925-5273(98)00222-9

Hill, C., \& Jones, G. (2009). Strategic Management, An Integrated approach (13th ed.). Boston: Houghton Mifflin Company.

Hitt, M. A., Hoskisson, E. R., \& Ireland, R. D. (2007). Management of Strategy: Concepts and Cases, South-Western (1st ed.). New York.

Houghton, R., El Sawy, O. A., Gray, P., Donegan, C., \& Joshi, A. (2004). Vigilant Information Systems for Managing Enterprises in Dynamic Supply Chains: Real-Time Dashboards at Western Digital. MIS Quarterly Executive, 3(1), 19-35.

Izza, S., Imache, R., Vincent, L., \& Lounis, Y. (2008). An Approach for the Evaluation of the Agility in the Context of Enterprise Interoperability. Enterprise Interoperability, 3, 3-14. http://dx.doi.org/10.1007/978-1-84800-221-0_1

Janssen, L. (2010). Organizational Agility in an Institutional Context. Supervisors: Drs. M.C.P. Nijssen \& Prof. dr. J. Paauwe.

Jaworski, B., \& Kohli, A. (1993). Market Orientation: Antecedents and Consequences. Journal of Marketing, 57(3), 52-70. http://dx.doi.org/10.2307/1251854

Markos, S., \& Sridevi, M. (2010). Employee Engagement: The Key to Improving Performance. International Journal of Business and Management, 5(12), 89-96.

Mathiassen, L., \& Pries-Heje, J. (2006). Business Agility and Diffusion of Information Technology. European Journal of Information Systems, 15, 116-119. http://dx.doi.org/10.1057/palgrave.ejis.3000610

McCarthy, I., Lawrence, T., Wixted, B., \& Gordon, B. (2010). A Multidimensional Conceptualization of Environmental Velocity. Academy of Management Review, 35(4), 604-626. http://dx.doi.org/10.5465/AMR.2010.53503029

Mehrabi, S., Siyadat, S., \& Allameh, S. (2013). Examining the Degree of Organizational Agility from Employees' Perspective (Agriculture-Jahad Organization of Shahrekord City). International Journal of Academic Research in Business and Social Sciences, 3(5), 315-323.

Miller, K., \& Bromiley, P. (1990). Strategic Risk and Corporate Performance: An Analysis of Alternative Risk Measure. Academy of Management Journal, 33(4), 756-779.

Nelson, A., \& Harvey, F. (1995). Technologies for Training and Supporting Your Agile Workforce. In Creating the Agile Organization: Models, Metrics and Pilots 4th Agility Forum Annual Conference.

Oosterhout, M., Waarts, E., \& Van, H. J. (2006). Change Factors Requiring Agility and Implications for It. European Journal of Information Systems, 15(2), 132-145. http://dx.doi.org/10.1057/palgrave.ejis.3000601

Overby, E., Bharadwaj, A., \& Sambamurthy, V. (2006). Enterprise Agility and the Enabling Role of Information Technology. European Journal of Information Systems, 15(2), 120-131. http://dx.doi.org/10.1057/palgrave.ejis.3000600

Park, Y. (2011). The Dynamics of Opportunity and Threat Management in Turbulent Environments: The Role Information Technologies. Doctor Dissertation.

Pathirage, C., Amaratunga, D., \& Haigh, R. (2007). Tacit knowledge and organizational performance. Journal of 
Knowledge Management, 11(1), 115-126.

Pavlou, P., \& El Sawy, O. (2010). The "Third Hand": IT-Enabled Competitive Advantage in Turbulence Through Improvisational Capabilities. Information Systems Research 21(3), 443-471. http://dx.doi.org/10.1287/isre.1100.0280

Privett, D. (1983). Working Knowledge. Boston Press, Harvard Business Review.

Robins, G., \& Wiersema, R. (1995). Organization \& Behavior, Princeton, New Jersey.

Sambamurthy, V., Bharadwaj, A., \& Grover, V. (2003). Shaping Agility through Digital Options: Reconceptualizing the Role of Information Technology in Contemporary Firms. MIS Quarterly, 27(2), 237-263.

Seo, D., \& Paz, A. (2008). Exploring the Dark Side of Is in Achieving Organizational Agility. Communication of the ACM, 51(11), 136-139. http://dx.doi.org/10.1145/1400214.1400242

Sharifi, H., \& Zhang, Z. (2001). Agile Manufacturing in Practice, Application of a Methodology. International

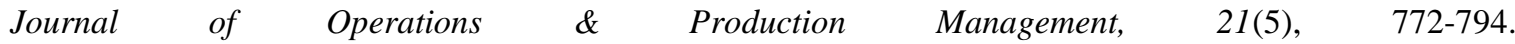
http://dx.doi.org/10.1108/01443570110390462

Sharifi, H., \& Zhang, Z. (1999). A methodology for achieving agility in manufacturing organisations, An introduction. International Journal of Production Economics, 62(1-2), 7-22. http://dx.doi.org/10.1016/S0925-5273(98)00217-5

Sherehiy, B. (2008). Relatioships Between Agility Strategy, Work Organization and Workforce Agility. Doctor Dissertation, University of Louisville.

Sherehiy, B., Karwowski, W., \& Layer, J. (2007). A Review of Enterprise Agility: Concepts, Frameworks, and Attributes. International Journal of Industrial Ergonomics, 37(5), 445-460. http://dx.doi.org/10.1016/j.ergon.2007.01.007

Smircich, L., \& Stubbart, C. (1985). Strategic Management in an Enacted World. Academy of Management Review, 10(4), 724-736.

Sull, D. (2009). How to Thrive in Turbulent Markets. Harvard Business Review, 87(2), 78-88.

Tallon, P. P., \& Pinsonneault, A. (2011). Competing perspectives on the link between strategic information technology alignment and organizational agility: Insights from a mediation model. MIS Quarterly, 35, 463-486.

Thomas, J., Clark, S., \& Gioia, D. (1993). Strategic Sensemaking and Organizational Performance: Linkages among Scanning, Interpretation, Action, and Outcomes. Academy of Management Journal, 36(2), 239-270. http://dx.doi.org/10.2307/256522

Tsourveloudis, N., \& Valavanis, K. (2002). On the Measurement of Enterprise Agility. Journal of Intelligent \& Robotic Systems, 33(3), 329-342. http://dx.doi.org/10.1023/A:1015096909316

Warr, P., \& Inceoglu, I. (2012). Job Engagement, Job Satisfaction, and Contrasting Associations With Person-Job Fit. Journal of Occupational Health Psychology, 17(2), 129-138. http://dx.doi.org/10.1037/a0026859

Wit, B., \& Meyer, R. (1998). Strategy: Process, Content, Context: An International Perspective. Thompson Business Press.

Yeganegi, K., \& Azar, M. (2012). The Effect of IT on Organizational Agility. Proceedings of the 2012 International Conference on Industrial Engineering and Operations Management, Istanbul, Turkey.

Yusuf, Y., Sarhadi, M., \& Gunasekaran, A. (1999). Agile Manufacturing: The Drivers, Concepts and Attributes. $\begin{array}{llll}\text { International Journal of Production } & \text { Economics, } & 62(1-2), & 33-43 .\end{array}$ http://dx.doi.org/10.1016/S0925-5273(98)00219-9

Zain, M., Rose, R., Abdullah, I., \& Masrom, M. (2005). The Relationship between Information Technology Acceptance and Organizational Agility in Malaysia. Information \& Management, 42, 829-839. http://dx.doi.org/10.1016/j.im.2004.09.001

\section{Copyrights}

Copyright for this article is retained by the author(s), with first publication rights granted to the journal. 
This is an open-access article distributed under the terms and conditions of the Creative Commons Attribution license (http://creativecommons.org/licenses/by/3.0/). 